OPEN ACCESS

Edited by:

Hai-Jing Zhong,

Jinan University, China

Reviewed by:

Gustavo Pompermaier Garlet, University of São Paulo, Brazil

Maja Miletic,

University of Belgrade, Serbia

*Correspondence:

Marcela Hernández

mhernandezrios@

odontologia.uchile.cl

Specialty section: This article was submitted to Inflammation,

a section of the journal

Frontiers in Immunology

Received: 24 January 2022 Accepted: 09 February 2022

Published: 01 March 2022

Citation:

Bordagaray MJ, Fernández $A$, Astorga J, Garrido M, Hernández $P$, Chaparro $A$, Lira MJ, Gebicke-Haerter $P$ and Hernández $M$ (2022) CpG Single-Site Methylation

Regulates TLR2 Expression in Proinflammatory PBMCs From Apical Periodontitis Individuals.

Front. Immunol. 13:861665. doi: 10.3389/fimmu.2022.861665

\section{CpG Single-Site Methylation Regulates TLR2 Expression in Proinflammatory PBMCs From Apical Periodontitis Individuals}

\author{
María José Bordagaray ${ }^{1,2}$, Alejandra Fernández ${ }^{1,3}$, Jessica Astorga ${ }^{1}$, Mauricio Garrido ${ }^{1,2}$, \\ Patricia Hernández ${ }^{1,2}$, Alejandra Chaparro ${ }^{4}$, María Jesús Lira ${ }^{5}$, Peter Gebicke-Haerter ${ }^{6}$ \\ and Marcela Hernández ${ }^{1,7 *}$ \\ ${ }^{1}$ Laboratory of Periodontal Biology, Faculty of Dentistry, Universidad de Chile, Santiago, Chile, ${ }^{2}$ Department of Conservative \\ Dentistry, Faculty of Dentistry, Universidad de Chile, Santiago, Chile, ${ }^{3}$ Faculty of Dentistry, Universidad Andres Bello, \\ Santiago, Chile, ${ }^{4}$ Department of Periodontology, Faculty of Dentistry, Centro de Investigación e Innovación Biomédica (CIIB), \\ Universidad de Los Andes, Santiago, Chile, ${ }^{5}$ Department of Orthopedic Surgery, Pontificia Universidad Católica de Chile, \\ Santiago, Chile, 6 Institute of Psychopharmacology, Central Institute of Mental Health, Faculty of Medicine, University of \\ Heidelberg, Mannheim, Germany, ${ }^{7}$ Department of Pathology and Oral Medicine, Faculty of Dentistry, Universidad de Chile, \\ Santiago, Chile
}

Introduction: Apical periodontitis (AP) is a common oral disease caused by the inflammatory destruction of the periapical tissues due to the infection of the root canal system of the tooth. It also contributes to systemic bacterial translocation, where peripheric mononuclear blood cells (PBMCs) can act as carriers. Toll-like receptor (TLR) 2 mediates the response to infection and activates inflammatory responses. DNA methylation can be induced by bacteria and contributes to the modulation of this response. Despite the evidence that supports the participation of PBMCs in immuneinflammatory disorders, the inflammatory profile and epigenetic regulatory mechanisms of PBMCs in AP individuals are unknown.

Aim: To determine TLR2 gene methylation and inflammatory profiles of PBMCs in AP.

Methods: Cross-sectional exploratory study. Otherwise, healthy individuals with AP $(n=27)$ and controls $(n=30)$ were included. PMBCs were isolated by a Ficoll gradient, cultured for 24 hours, and both RNA and DNA were extracted. DNA was bisulfite-treated, and specific sites at the promoter region of the TLR2 gene were amplified by qPCR using validated primers. To verify its amplification, agarose gels were performed. Then, the PCR product was sequenced. mRNA expression of TLR2 was determined by qPCR. The soluble levels of 105 inflammatory mediators were first explored with Proteome Profiler Human Cytokine Array Kit. Consequently, tumor necrosis factor (TNF)- $\alpha$, interleukin (IL)-6, IL-10, IL-6R $\alpha$, IL-1 $\beta$, and IL-12p70 levels were measured by Multiplex assay.

Results: PBMCs from individuals with AP demonstrated a proinflammatory profile showing higher soluble levels of TNF- $\alpha, \mathrm{IL}-6$, and IL-1 $\beta$ compared to controls $(p<0.05)$. Higher TLR2 expression and higher global methylation pattern of the promoter region of the gene were found in AP compared to controls $(p<0.05)$. The CpGs single-sites at 
positions -166 and -146 were completely methylated, while the site -102 was totally unmethylated, independently of the presence of AP. DNA methylation of CpG single-sites in positions -77 and +24 was positively associated with TLR2 expression.

Conclusions: PBMCs from AP subjects show a hyperinflammatory phenotype and TLR2 upregulation in association with single CpG-sites' methylation from the TLR2 gene promoter, thereby contributing to a sustained systemic inflammatory load in individuals with periapical endodontic diseases.

Keywords: periapical periodontitis, toll-like receptor 2, CpG island, DNA methylation, RNA messenger, leukocytes, mononuclear

\section{INTRODUCTION}

Apical periodontitis (AP) is among the main causes of tooth loss and is typified by the inflammatory destruction of the periapical tissues as a consequence of the infection of the root canal system of the tooth (1). Its hallmark is the development of an apical lesion of endodontic origin (ALEO) (2), and it has been identified as an independent contributor to low-grade systemic inflammation, and a non-classical risk factor for noncommunicable diseases (2).

The pathogenesis of AP is mediated by the host-pathogen interactions, in which, toll-like receptors (TLR) play a pivotal role. TLRs are a family of receptors activated by damageassociated molecular patterns (DAMPs) and pathogenassociated molecular patterns (PAMPs) (3). Among them, TLR2 classically recognizes lipoteichoic acid from Grampositive bacteria (4), but it also is involved in the recognition of lipopolysaccharide from Gram-negative bacteria $(5,6)$. For this reason, oral pathogens like Porphyromonas (P.) gingivalis and $P$. endodontalis, can trigger the TLR2 pathway $(7,8)$. The interaction TLR2-ligand activates intercellular signaling that induces nuclear factor $\kappa-\mathrm{B}(\mathrm{NF} \kappa \mathrm{B})$ translocation to the nucleus and the consequent inflammatory cascade activation (9). The expression of TLR2 can be regulated by transcriptional changes that depend on epigenetic modifications in ALEOs (10).

Epigenetics can regulate the activation of the immune cell in response to infection by transcriptional reprogramming $(11,12)$. These modifications are characterized as being stably inherited to the cell progeny without altering the DNA sequence. Epigenetic modifications involve histone post-translational changes, microRNA interference, and DNA methylation (13). DNA methylation, the addition of a methyl group on the fifth carbon of a DNA cytosine residue (14), is often found in rich $\mathrm{C}$ and $\mathrm{G}$ dinucleotide $(\mathrm{CpG})$ regions and can be induced by bacteria to either allow pathogen persistence or promote host defense (11). Gene silencing is the most frequent regulatory mechanism associated with DNA hypermethylation, but a dual regulatory function has also been proposed (15). TLR2 contains a $\mathrm{CpG}$ island being highly susceptible to epigenetic regulation. It is also overexpressed at local oral tissues in periodontitis (16) and AP (10). The higher expression of TLR2 in ALEOs is associated with a hypomethylated DNA pattern of the promoter region and specific CpG single-sites, supporting the epigenetic regulation in AP (10).

Recent evidence sustains that AP courses with low-grade systemic inflammation $(2,17)$; moreover, endodontic bacteria and/or their products, such as $P$. endodontalis, can invade the peri radicular tissues and translocate to distant sites within peripheric blood mononuclear cells (PBMCs) (18). In this context, the internalization of bacteria or their antigens might result in mononuclear cell activation via TLR2 recognition (19), and reasonably contribute to a higher systemic inflammatory burden. Despite the evidence that supports the participation of PBMCs in systemic immune-inflammatory diseases, such as rheumatoid arthritis or cardiovascular diseases (20-23), the behavior and regulatory mechanisms of PBMCs in AP are currently unknown. In this study, we aimed to determine the TLR2 gene methylation and inflammatory profiles of PBMCs in AP.

\section{MATERIALS AND METHODS}

\section{Study Design}

This analytic cross-sectional exploratory study was conducted under the approval of the Ethics-Scientific Committee of the Central Metropolitan Health Service (Number 2017/70) and from the Faculty of Dentistry, Universidad de Chile (Number 2016/08). All the volunteers were informed about the objectives and procedures of the study and signed the informed consent. All procedures followed the ethical standards of the institutional and/or national research committees and were under the 1964 Helsinki declaration and its later amendments.

\section{Study Participants}

Otherwise healthy individuals aged between 18-40 years old consulting at the Dental Clinic, Faculty of Dentistry, Universidad de Chile were enrolled between 2016-2020 if they had a clinical diagnosis of primary AP (1) and no concomitant systemic diseases. The volunteers had one or more teeth with a clinical diagnosis of asymptomatic (AAP) or symptomatic apical periodontitis (SAP). The diagnosis was confirmed by a negative response to pulp sensitivity tests, the absence or presence of pain to dental percussion, respectively (1), and the presence of $\geq 1$ ALEO equal to or greater than $3 \mathrm{~mm}$ in diameter equivalent to a 
periapical index $\geq 3$ (24). Controls met the same criteria in the absence of AP. Exclusion criteria were severe periodontitis, pregnancy, body mass index $\geq 30 \mathrm{~kg} / \mathrm{m}^{2}$, and antibiotic and/or anti-inflammatory drug consumption three months before the study (2).

\section{Clinical Evaluation of Participants}

General health assessment and medical history were conducted by the endodontist and a trained nurse technician. Age, sex, educational level, smoking habit, and classic cardiovascular risk factors $(25,26)$, were recorded in pre-established charts. Individuals with a history of non-communicable diseases were excluded from the study and referred to a medical center for further evaluation.

Oral clinical evaluations were carried out by a qualified general dentist (C.V.), a periodontist (P.H.), an endodontist (M.G). The ALEO size was determined as the mean of vertical and horizontal diameters $(\mathrm{mm})$. Full-mouth radiographic evaluations were obtained. Intraoral parameters including periodontal probing depth (PPD) and clinical attachment levels (CAL) were determined with a periodontal probe (UNC15, Hu-Friedy, USA) in six sites per tooth. All the enrolled patients received hygiene instruction, full-mouth ultrasonic scaling, and coronal prophylaxis before entering the study. The subjects with AP diagnosis were properly treated (M.G) after the sample collection.

\section{Samples}

Fasting blood samples were obtained from AP $(n=27)$ and healthy controls volunteers $(n=30)$. The samples were collected by venipuncture of the antecubital vein by a qualified technician (27). Fractions of the collected blood samples were submitted to the clinical laboratory of the University of Chile Hospital for the determination of glycated hemoglobin levels (HbAlc) and lipid profiles. The rest of the samples were submitted and processed in the Laboratory of Periodontal Biology for isolation of PBMCs using Ficoll-Paque Premium 1.073 (GE Healthcare ${ }^{\circledR}$ ) according to the manufacturer's instructions.

\section{Profiling of Secreted Inflammatory Proteins}

Isolated PBMCs from individuals with AP as well as controls were cultured in a 96-well plate in a $2 \times 10^{5}$ cell density and incubated at $37^{\circ} \mathrm{C}$ and $5 \% \mathrm{CO}_{2}$ in RPMI-1640 medium. After 24 hours, the supernatants were recovered and the inflammatory profile of PBMCs first was explored by a commercial Proteome Profiler Human Cytokine Array Kit, identifying 105 soluble inflammatory proteins simultaneously ( $\&$ \& system Inc., Minneapolis, USA). Briefly, samples were mixed with a cocktail of biotinylated detection antibodies fixed on a membrane-based sandwich immunoassay, according to the manufacturer's instructions. Three independent samples per group were loaded in duplicates. The captured proteins were visualized by chemiluminescence and semi quantification was performed by densitometric scanning (Bruker MI SE, Billerica, MA, USA). The intensity was determined by the mean pixel density of the duplicate spots that represent each cytokine.
The negative control was the clear area of the membrane. Also, the levels of tumor necrosis factor (TNF)- $\alpha$, interleukin (IL)- $1 \beta$, IL-6, IL-6R $\alpha$, IL-12p70, and IL-10 were measured by Multiplex assay (R\&D System Inc., Minneapolis, USA) using a Luminex platform (Milliplex MAGPIX ${ }^{\circledR}$ System, Merck Millipore, Massachusetts, USA), following the manufacturers' recommendations. The data were analyzed by the MILLIPLEX AnalystR software (v5.1, Viagene Tech, Carlisle, MA, USA).

\section{DNA and RNA Isolation}

DNA was purified from PBMCs using the DNeasy isolation kit (QIAGEN Inc., Valencia, CA, USA) and RNA was extracted with TRIzol Reagent (Invitrogen ${ }^{\mathrm{TM}}$ ), following the respective manufacturer's instructions. The quality and concentration of DNA and RNA were quantified using a spectrophotometer (BioTek, Winooski, VT, USA) in the ratio of 260:280. A reverse transcription kit (Thermo Fisher Scientific, Carlsbad, CA, USA) was used for synthesizing the single-stranded cDNA from the RNA samples $(8 \mu \mathrm{l})$.

\section{mRNA Expression Level}

The mRNA expression levels of TLR2 were determined by the amplification of $50 \mathrm{ng}$ of cDNA by qPCR through KAPA SYBR ${ }^{\circledR}$ FAST qPCR Kits (KAPA Biosystems), using the forward sequence 5'-CTCTCGGTGTCGGAATGTC-3' and the reverse sequence 3'-AGGATCAGCAGGAACAGAGC-5', as previously reported (10). Amplification was performed at $95^{\circ} \mathrm{C}$ for $30 \mathrm{~s}, 40$ cycles at $95^{\circ} \mathrm{C}$ for $30 \mathrm{~s}$, and $60^{\circ} \mathrm{C}$ for $30 \mathrm{~s}$. Additionally, a melting curve was run from 60 to $95^{\circ} \mathrm{C}$ to identify the presence of nonspecific products. Gene expression was normalized by $18 \mathrm{~S}$ ribonucleic RNA expression levels in controls and calculated by the $2-\Delta \Delta \mathrm{Ct}$ method (28).

\section{DNA Methylation Analysis}

Purified DNA (200 ng) from each sample was bisulfite-treated (EZ DNA Methylation-Direct ${ }^{\mathrm{TM}}$ Kit, Zymo Research Irvine, CA, USA). Bisulfited DNA was amplified by KAPA SYBR ${ }^{\circledR}$ Fast qPCR Kits (KAPA Biosystems, Woburn, MA, USA) with validated primer set for TLR2 promoters CpG island: forward sequence 5'TAAGGGCGGGAGTTTGTTGGGAAGTAC-3' and reverse sequence 3'-CTCCGAACCGACCTACCCGAAACTAAA-5', as previously reported (10). The selected primers for original or bisulfited DNA were obtained from Gene Bank: http://www.ncbi. nlm.nih.gov/nuccore/NC_000004.12?report=genbank\&from= 153684256\&to $=15370609$ by Methprimer program (http://www. urogene.org/cgi-bin/methprimer/methprimer.cgi). The PCR amplified product integrity was determined on agarose gels (2\%) and submitted to Sanger sequencing service (Macrogen, Seoul, Korea). The sequencing results were analyzed with the BiQ Analyzer program and expressed as the relative frequency of global methylation (methylated $\mathrm{CpG}$ sites/the total sites) and single-CpG methylated sites within the $\mathrm{CpG}$ island from the TLR2 gene promoter.

\section{Statistical Analysis}

Data distribution of numerical variables was assessed by the Shapiro-Wilk test. Comparisons between AP and controls were 
analyzed by $t$-test or Mann-Whitney U-test according to data distribution. Spearman's correlation was used to evaluate the association between quantitative variables. The comparison of categorical variables was performed with the chi-square test. To explore the associations between TLR2 global and CpG singlesite's methylation, as independent variables, and TLR2 mRNA expression as the outcome variable independently of potential confounders, we ran linear bivariate and multiple regression models using backward stepwise regression, removing the covariates with $\mathrm{p} \geq 0.2$. To explore the influence of periapical inflammation and other potential exposure factors on the global methylation of the TLR2 gene promoter's CpG island, we performed bivariate fractional regression for potential confounders and then fit the models including those covariates with significant $\mathrm{p}$ values $(\mathrm{p}<0.1)$. To facilitate interpretation, we estimated and presented the marginal effects. Statistical analyses were performed with Stata statistical package 12 (Stata-Corp. LP, TX, USA). All figures were constructed on GraphPad Prism 9 software (Graph-Pad Software Inc., San Diego, CA, USA).

\section{RESULTS}

General, intraoral, and serum parameters of enrolled volunteers are shown in Table 1. Age, sex, and smoking habit were higher with AP than controls $(\mathrm{p}<0.05)$, while the rest of the variables were evenly distributed among groups. The secreted inflammatory profile of PBMCs is shown in Figure 1. A proinflammatory phenotype (Figures 1A, B) composed of 17 upregulated and 7 down-regulated inflammatory mediators was determined in AP versus controls $(\mathrm{p}<0.05)$. Also, the concentrations $(\mathrm{pg} / \mathrm{mL})$ of inflammatory cytokines commonly associated with systemic inflammation were determined (Figures 1C-H). In AP the levels of the pro-inflammatory cytokines TNF- $\alpha$, IL- $1 \beta$, and IL-6 were significantly higher than controls $(\mathrm{p}=0.029, \mathrm{p}=0.032, \mathrm{p}=0.017$; respectively). On the other hand, the levels of IL-6R $\alpha$, IL-12p70, and IL-10 did not show differences between the study groups $(\mathrm{p}=0.555, \mathrm{p}=0.426$, $\mathrm{p}=0.117$; respectively).

Analysis of TLR2 expression revealed significantly higher mRNA expression levels in AP subjects compared to the control group (Figure $\mathbf{2 A} ; \mathrm{p}=0.013$ ). The association between TLR2 gene expression and TNF- $\alpha$, IL-1 $\beta$, IL-6, IL-6R $\alpha$, IL-12p70 and IL-10 levels resulted in moderate and low correlations ( $r=$ $0.34,0.16,0.37,0.19,-0.22,0.24$, respectively; $\mathrm{p}>0.05)$. The epigenetic regulation of the TLR2 gene was explored by determining the methylation status of the CpG island at the gene promoter, localized between positions -166 to +38 , as shown in Figure 2B. A higher global methylation pattern of the gene promoter was found in AP, compared to healthy controls $(\mathrm{p}=0.043)$ with medians (interquartile range) of $20.8 \%$ (15.3) and $16.7 \%$ (9.2), respectively (Figure 2C). The methylation frequencies of the $\mathrm{CPG}$ single-sites are shown in Figure 2D. While the sites -166 and -146 were completely methylated, the site - 102 was totally unmethylated, independently of the presence of the periapical disease; the rest of the CpG single-sites on the other hand were highly variable regarding their methylation status.

To further understand the influence of the TLR2 promoter's methylation status over its transcriptional activity, linear regression modeling was performed (Table 2). The global methylation status alone did not associate with TLR2 transcriptional activity $(\mathrm{p}=0.42)$. At the site level, CpG methylated positions at -77 and +24 were positively associated with TLR2 transcriptional activity in bivariate models $(\mathrm{p}=0.036$ and 0.034 , respectively) and multivariate model ( $\mathrm{p}=0.005$ and 0.014 , respectively), and the later model explained $33 \%$ of the variability.

Finally, potential modifying factors of TLR2 promoter's gene methylation were explored (Table 3). Among all variables, the periapical diagnosis and aging were identified to influence the global methylation of the TLR2 gene promoter. Bivariate analysis showed that the global methylation was increased by the presence of ALEO $(p=0.022)$ and aging $(p=0.0004)$. However, when including both covariates in the multivariate model, only

TABLE 1 | Sociodemographic, general, oral, and serum parameters of study individuals with apical periodontitis (AP) and healthy controls.

\begin{tabular}{|c|c|c|c|}
\hline & Controls $(n=30)$ & AP $(n=27)$ & $p$ value \\
\hline Age (years) & $22(6)$ & $25(15)$ & 0.02 \\
\hline Females (n,\%) & $15(50 \%)$ & $21(77.8 \%)$ & 0.03 \\
\hline Smokers (n,\%) & $5(17.2 \%)$ & $13(48.1 \%)$ & 0.01 \\
\hline Educational level & 3 & 3 & 0.59 \\
\hline High blood pressure (n, \%) & $2(7.4 \%)$ & 1 (3.3\%) & 0.49 \\
\hline $\mathrm{PD}(\mathrm{mm})^{\# \#}$ & $2.05(0.43)$ & $2.08(0.56)$ & 0.34 \\
\hline $\mathrm{CAL}(\mathrm{mm})^{\# \#}$ & $1(0.83)$ & $1(1.36)$ & 0.12 \\
\hline Number of apical lesions ${ }^{\# \#}$ & - & $1.14(0.4)$ & - \\
\hline Apical lesions size $(\mathrm{mm})^{\#}$ & - & $8(6.5)$ & - \\
\hline Total cholesterol (mg/dL) & $161(53)$ & $160(62)$ & 0.54 \\
\hline LDL cholesterol (mg/dL) & $83(37)$ & $84.4(49.8)$ & 0.70 \\
\hline HDL cholesterol (mg/dL) & $56(16)$ & $54(21)$ & 0.23 \\
\hline Triglycerides (mg/dL) & $92(60)$ & $121(97)$ & 0.88 \\
\hline $\mathrm{HbA} 1 \mathrm{c}^{\# \#}$ & $5.1(0.16)$ & $5.2(0.2)$ & 0.09 \\
\hline
\end{tabular}

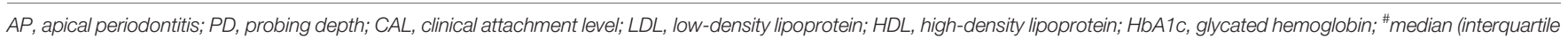
range); "\#mean(standard deviation); bold: $p<0.05$. 
A
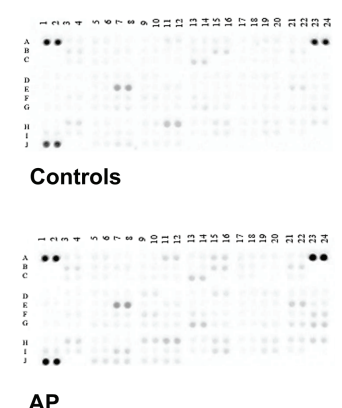

AP

C

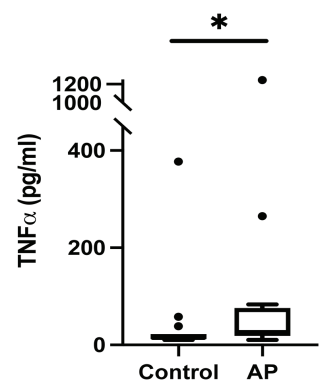

F

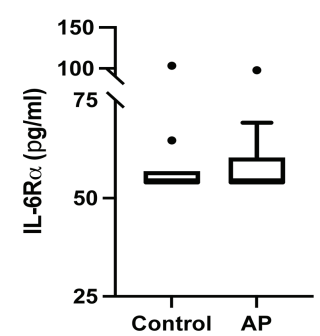

B

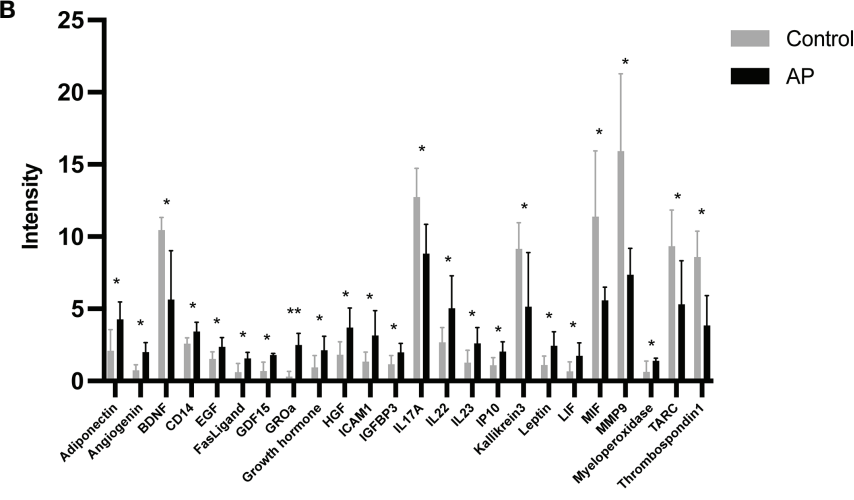

D

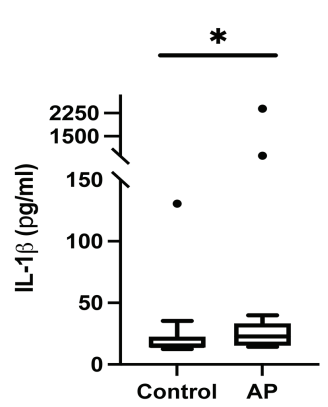

E

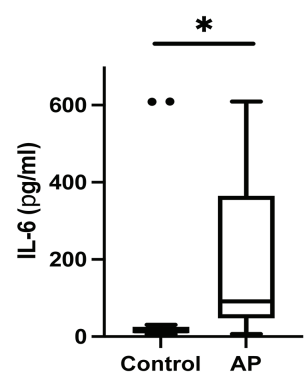

G

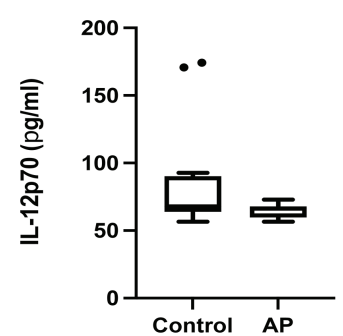

H

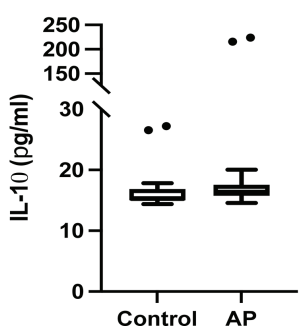

FIGURE 1 | Profiling of secreted inflammatory proteins in PBMCs from apical periodontitis and control individuals. (A) Inflammatory protein profile (B) Relative levels of

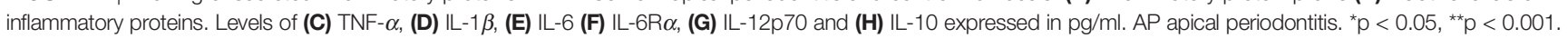

aging remained associated. The global methylation was increased by +12 percentage points by each year $(\mathrm{p}=0.011)$. Also, age correlated positively with the promoter's global methylation $(\mathrm{rho}=0.44 ; \mathrm{p}=0.0012)$.

\section{DISCUSSION}

AP has largely been considered as a local infection that causes the inflammation and disruption of the periapical tissues, though recent evidence demonstrates that ALEOs also contribute to the systemic bacterial and inflammatory burden, acting as a nonclassic risk factor for non-communicable diseases $(2,18)$. In the present study, we show for the first time that PBMCs present a pro-inflammatory phenotype and overexpress TLR2 in AP individuals in association with the gene promoter's methylation.
PBMCs, which include monocytes, natural killers, and $\mathrm{T}$ and B lymphocytes, are key cells in the preservation of systemic homeostasis and defense against infection. Furthermore, their cytokine production has been proposed to reflect the activity of several immune-inflammatory diseases (20-23). Our results showed that PBMCs from AP individuals have a global proinflammatory secretory profile with significantly higher levels of TNF- $\alpha$, IL- $1 \beta$, and IL- 6 in comparison with healthy controls. Despite there being no reports in AP, PBMCs from individuals with periodontitis have also shown a proinflammatory profile with enhanced secretion of interferon$\gamma$, IL-6, IL-12p70, IL-17, and monocyte chemoattractant protein1 versus their healthy counterparts (29). In line with this, PBMCs from patients with periodontitis stimulated in vitro with LPS of Escherichia coli, have also demonstrated a proinflammatory secretory pattern with higher levels of the cytokine's TNF- $\alpha$ 
A

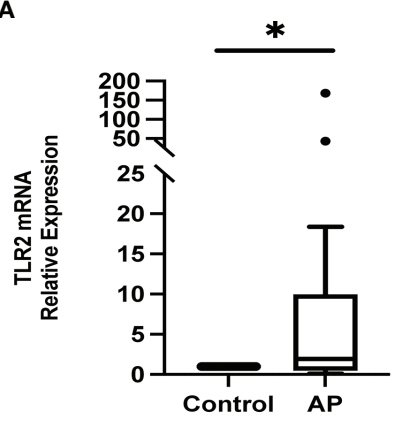

C

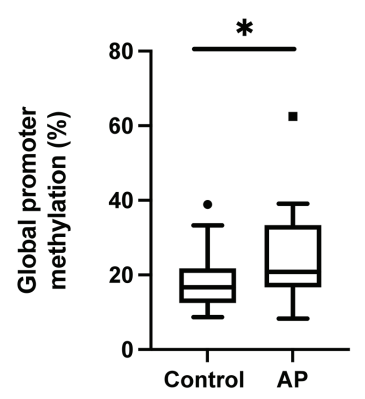

B

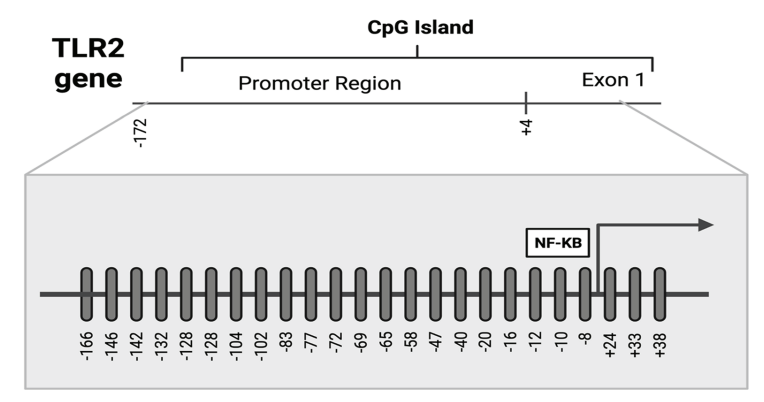

D

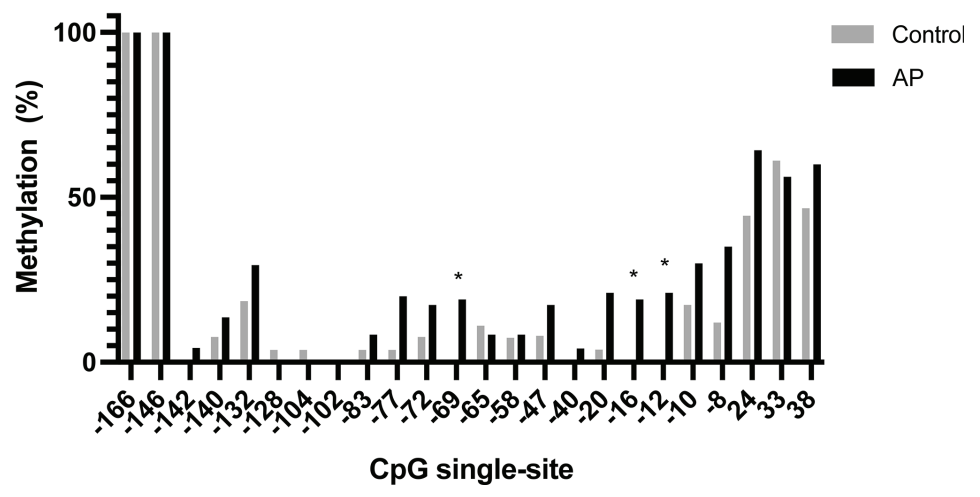

FIGURE 2 | Expression levels and methylation profile of TLR2 in PBMC from apical periodontitis and control individuals. (A) mRNA relative expression of TLR2. The expression data were normalized to $18 \mathrm{~S}$ rRNA and relative to controls, using the differences between $2-\triangle \Delta C T .{ }^{*} p=0.013$. (B) Schematic representation of the human $\mathrm{CpG}$ single-sites from TLR2 gene promoter. (C) Global promoter methylation frequency (\%). ${ }^{*} \mathrm{p}=0.043$ (D) CpG single-site methylation frequency (\%). AP apical periodontitis.

and IL-6, among others, in comparison with PBMCs from healthy individuals (30). TNF- $\alpha$ and IL- 6 are associated with pro-inflammatory and bone resorptive local responses $(31,32)$, as well as C-reactive protein (CRP) synthesis, which is involved in systemic inflammation. Moreover, higher plasma levels of these cytokines have been associated with the development of cardiovascular events (33). In our study, the higher levels of TNF- $\alpha$, IL- $1 \beta$, and IL- 6 in PBMCs from AP individuals were also accompanied by the upregulation of several cardiovascular disease biomarkers like adiponectin and angiogenin (34). Overall, global PBMCs analysis revealed an active proinflammatory state in PBMCs from AP individuals, thus contributing to the inflammatory burden and its long-term consequences. Further evaluation of the specific cell subsets contributing to this inflammatory phenotype will contribute to unveil systemic inflammation associated with oral infections.

TLR2 plays an important role in the recognition of microbial stimuli and the triggering of innate and adaptive immune responses. The local expression of TLR2 in periapical tissues has been associated with the presence and progression of AP. It has been demonstrated that TLR2 expression increases along with the development and progression of ALEOs at different time points
(35). TLR2 is also overexpressed in human ALEOs particularly in symptomatic AP, which can represent the active form of the disease, compared to asymptomatic AP and healthy tissues (10). Regarding TLR2 in the systemic context, the evidence supports that TLR2 is upregulated in PBMCs of individuals with inflammatory non-communicable diseases $(36,37)$. Also, the transcription of this pattern recognition receptor in PBMCs is downregulated after periodontal therapy in periodontal disease individuals (38). These data agree with our results where we showed that TLR2 is overexpressed in PBMCs from AP individuals in comparison with controls, supporting the role of ALEOs in PBMC activation.

DNA methylation, one of the main epigenetic modulating mechanisms, has been reported to regulate several chronic inflammatory pathologies $(12,39,40)$. The CpG islands are highly susceptible to methylation reprogramming. In the case of the TLR2 gene, it comprises the promoter region, exon 1, and part of intron 1 (41). Most available evidence supports that TLR2 expression and the methylation status of the gene promoter have an inverse relation (10,42-44). However, our study does not support similar findings in PBMCs from AP individuals. In line with our results, the expression levels of TLR2 were independent of the gene's methylation pattern in the HUVEC cell line 
TABLE 2 | Influence of the TLR2 promoter's methylation status in gene expression.

\begin{tabular}{|c|c|c|c|}
\hline \multicolumn{4}{|c|}{ A. Global methylation status } \\
\hline \multirow{2}{*}{ Variable } & \multicolumn{3}{|c|}{$(N=50)$} \\
\hline & Coef \pm SE & & p-value \\
\hline Global methylation (\%) & $-0.02 \pm 0.019$ & & 0.42 \\
\hline
\end{tabular}

Coef, coefficient; SE, standard error; bold: $p<0.05$.

\begin{tabular}{lcc}
\hline B. CpG single-sites & & \\
\hline Site & & Ln TLR2 mRNA relative expression \\
\cline { 2 - 3 } & Coef \pm SE & p-value \\
\hline$C p G-77^{1}$ & $1.35 \pm 0.63$ & 0.095 \\
$R^{1}$ & $1.05 \pm 0.47$ & 0.036 \\
$C p G+24^{1}$ & & 0.141 \\
$R^{1}$ & $2.15 \pm 0.71$ & $\mathbf{0 . 0 3 4}$ \\
$C p G-77^{2}$ & $1.11 \pm 0.42$ & $\mathbf{0 . 0 0 5}$ \\
CpG $+24^{2}$ & & 0.332 \\
\hline R-squared & & $\mathbf{0 . 0 1 4}$ \\
\hline
\end{tabular}

${ }^{1}$ Bivariate (CpG -77 N=46; CpG $+24 N=32$ ); ${ }^{2}$ Multivariate Model ( $N=31$ ), including both covariates shown. Coef, coefficient; $S E$, standard error; bold: $p<0.05$.

TABLE 3 | Modifiers of TLR2 promoter's methylation status.

\begin{tabular}{|c|c|c|}
\hline Exposure variables & Fractional point change (CI 95\%) & $\mathrm{p}$-value \\
\hline PA Diagnosis (ALEO) $)^{1}$ & $0.03(0.002-0.06)$ & 0.022 \\
\hline Age (years) ${ }^{1}$ & $0.15(0.06-0.23)$ & 0.0004 \\
\hline PA Diagnosis (ALEO) $)^{2}$ & $0.02(-0.01-0.05)$ & 0.162 \\
\hline Age $(\text { years })^{2}$ & $0.12(0.02-0.21)$ & 0.011 \\
\hline
\end{tabular}

${ }^{1}$ Bivariate model. ${ }^{2}$ Multivariate model using periapical (PA) diagnosis and age as covariates. $N=51$. Cl, Confidence Interval; bold: $p<0.05$.

stimulated with TNF- $\alpha$ (45). Also, the methylation status of the TLR2 promoter's region showed no differences among normal and inflamed human pulp tissue (46), despite the upregulation of TLR2 having been previously reported (47). Overall, TLR2 DNA methylation might cause activation or repression depending on the stimulus $(48,49)$ in a tissue/cell-specific manner $(50,51)$.

Emerging evidence supports that DNA methylation can also act by regulating the binding of transcription factors (TF) or methylCpG-binding proteins in a CpG site-specific manner (52-54). Particularly in ALEOs, unmethylated CpG single-sites - 10 and - 12 are associated with transcriptional upregulation of TLR2 (10). Interestingly, these $\mathrm{CpG}$ single-sites are close to the $\mathrm{NF} \kappa \mathrm{B}$ binding sequence. Accordingly, when unmethylated they allow the TF binding and gene transcription (41). In our study, the methylation of $\mathrm{CpG}$ single-sites -77 and +24 in PBMCs was positively associated with TLR2 mRNA expression. Despite there being no previous reports from TLR2, methylated CpG single-sites have also been associated with the upregulation of gene expression. FGFR3 gene expression demonstrated a positive correlation between $\mathrm{CpG}$ single-sites promoters' methylation in uterine corpus endometrial carcinoma and breast invasive carcinoma (55). The mechanisms supporting a direct association between DNA methylation and transcription upregulation remain to be elucidated, but it has been proposed that methylated $\mathrm{CpG}$ single-sites could create new binding sites for TFs favoring the initiation of transcription activity (56).

A few studies sustain that aging is associated with global hypermethylation of $\mathrm{CpG}$ islands (57). In our study the methylation of TLR2 promoter in PBMCs was influenced by aging, being the main factor of the higher global methylation in AP in comparison with controls. The link between aging and hypermethylation is complex and multivariable, but it has been proposed that it could be attributed to the accumulation of stochastic methylation events (58) and the down-regulation of ten-eleven translocation demethylases (59).

Concluding, PBMCs show a hyperinflammatory phenotype and TLR2 upregulation in AP, which in turn, is influenced by the methylation of single CpG-sites from the TLR2 gene promoter, contributing to a sustained systemic inflammatory load in individuals with periapical endodontic diseases.

\section{DATA AVAILABILITY STATEMENT}

The original contributions presented in the study are included in the article/supplementary material. Further inquiries can be directed to the corresponding author.

\section{ETHICS STATEMENT}

The studies involving human participants were reviewed and approved by the Ethics-Scientific Committee of the Central 
Metropolitan Health Service (N 2017/70) and from the Faculty of Dentistry, Universidad de Chile (N2016/08). The patients/ participants provided their written informed consent to participate in this study.

\section{AUTHOR CONTRIBUTIONS}

$\mathrm{MH}, \mathrm{MG}, \mathrm{AC}$, and PG-H: conceptualization and design. $\mathrm{MH}$, $\mathrm{MB}$, and ML: data curation. $\mathrm{MH}$ : Funding acquisition. $\mathrm{MH}, \mathrm{AF}$, and $\mathrm{MB}$ : Formal analysis. $\mathrm{MB}, \mathrm{AF}$, and $\mathrm{JA}$ : laboratory experiments. $\mathrm{MH}$ : Project administration. $\mathrm{MB}$ and $\mathrm{MH}$ : design the figures. $\mathrm{MH}$ : Resources. $\mathrm{MH}$ : Software. $\mathrm{MG}, \mathrm{MH}$, and $\mathrm{PH}$ : Supervision. MB, AF, and MH: Writing manuscript. All authors critically reviewed and approved the manuscript.

\section{REFERENCES}

1. Gutmann JL, Baumgartner JC, Gluskin AH, Hartwell GR, Walton RE. Identify and Define All Diagnostic Terms for Periapical/Periradicular Health and Disease States. J Endod (2009) 35(12):1658-74. doi: 10.1016/j.joen. 2009.09.028

2. Garrido M, Cárdenas AM, Astorga J, Quinlan F, Valdés M, Chaparro A, et al. Elevated Systemic Inflammatory Burden and Cardiovascular Risk in Young Adults With Endodontic Apical Lesions. J Endodontics (2019) 45(2):111-5. doi: 10.1016/j.joen.2018.11.014

3. Kono H, Rock KL. How Dying Cells Alert the Immune System to Danger. Nat Rev Immunol (2008) 8(4):279-89. doi: 10.1038/nri2215

4. Takeuchi O, Hoshino K, Kawai T, Sanjo H, Takada H, Ogawa T, et al. Differential Roles of Tlr2 and Tlr4 in Recognition of Gram-Negative and Gram-Positive Bacterial Cell Wall Components. Immunity (1999) 11(4):44351. doi: 10.1016/s1074-7613(00)80119-3

5. Hirschfeld M, Weis JJ, Toshchakov V, Salkowski CA, Cody MJ, Ward DC, et al. Signaling by Toll-Like Receptor 2 and 4 Agonists Results in Differential Gene Expression in Murine Macrophages. Infect Immun (2001) 69(3):147782. doi: 10.1128/IAI.69.3.1477-1482.2001

6. Kirikae T, Nitta T, Kirikae F, Suda Y, Kusumoto S, Qureshi N, et al. Lipopolysaccharides (Lps) of Oral Black-Pigmented Bacteria Induce Tumor Necrosis Factor Production by Lps-Refractory C3h/Hej Macrophages in a Way Different From That of Salmonella Lps. Infect Immun (1999) 67 (4):1736-42. doi: 10.1128/iai.67.4.1736-1742.1999

7. Tang Y, Sun F, Li X, Zhou Y, Yin S, Zhou X. Porphyromonas Endodontalis Lipopolysaccharides Induce Rankl by Mouse Osteoblast in a Way Different From That of Escherichia Coli Lipopolysaccharide. J Endod (2011) 37 (12):1653-8. doi: 10.1016/j.joen.2011.08.015

8. Harokopakis E, Albzreh MH, Martin MH, Hajishengallis G. Tlr2 Transmodulates Monocyte Adhesion and Transmigration Via Rac1- and Pi3k-Mediated Inside-Out Signaling in Response to Porphyromonas Gingivalis Fimbriae. J Immunol (2006) 176(12):7645-56. doi: 10.4049/ jimmunol.176.12.7645

9. de Oliviera Nascimento L, Massari P, Wetzler L. The Role of Tlr2 in Infection and Immunity. Front Immunol (2012) 3:79. doi: 10.3389/fimmu.2012.00079

10. Fernández A, Veloso P, Astorga J, Rodríguez C, Torres VA, Valdés M, et al. Epigenetic Regulation of Tlr2-Mediated Periapical Inflammation. Int Endod J (2020) 53(9):1229-37. doi: 10.1111/iej.13329

11. Bierne H, Hamon M, Cossart P. Epigenetics and Bacterial Infections. Cold Spring Harb Perspect Med (2012) 2(12):a010272. doi: 10.1101/cshperspect.a 010272

12. Qin W, Scicluna BP, van der Poll T. The Role of Host Cell DNA Methylation in the Immune Response to Bacterial Infection. Front Immunol (2021) 12:696280. doi: 10.3389/fimmu.2021.696280

13. Zhang L, Lu Q, Chang C. Epigenetics in Health and Disease. Adv Exp Med Biol (2020) 1253:3-55. doi: 10.1007/978-981-15-3449-2_1

\section{FUNDING}

This study was funded by FONDECYT grants 1160741 and 1200098 from ANID, the Chilean government. MB is a recipient of the scholarship ANID 21210551, from the Chilean Government. AF is a recipient of the scholarship CONICYT 21181377, from the Chilean Government. MG is a recipient of the scholarship ANID 21210509, from the Chilean Government.

\section{ACKNOWLEDGMENTS}

We want to thank Bernarda Parada for her contribution to the recruiting and sampling procedures and we especially dedicate this manuscript to the memory of Macarena Valdés.

14. Laird PW. Principles and Challenges of Genomewide DNA Methylation Analysis. Nat Rev Genet (2010) 11(3):191-203. doi: 10.1038/nrg2732

15. Lyko F. The DNA Methyltransferase Family: A Versatile Toolkit for Epigenetic Regulation. Nat Rev Genet (2018) 19(2):81-92. doi: 10.1038/ nrg. 2017.80

16. Rojo-Botello NR, García-Hernández AL, Moreno-Fierros L. Expression of Toll-Like Receptors 2, 4 and 9 Is Increased in Gingival Tissue From Patients With Type 2 Diabetes and Chronic Periodontitis. J Periodontal Res (2012) 47 (1):62-73. doi: 10.1111/j.1600-0765.2011.01405.x

17. Georgiou AC, Crielaard W, Ouwerling P, McLean W, Lappin DF, van der Waal SV. The Influence of Apical Periodontitis on the Concentration of Inflammatory Mediators in Peripheral Blood Plasma and the Metagenomic Profiling of Endodontic Infections: Study Design and Protocol. Contemp Clin Trials Commun (2021) 21:100686. doi: 10.1016/j.conctc.2020.100686

18. Bordagaray MJ, Fernández A, Garrido M, Astorga J, Hoare A, Hernández M. Systemic and Extraradicular Bacterial Translocation in Apical Periodontitis. Front Cell Infect Microbiol (2021) 11:649925. doi: 10.3389/fcimb.2021.649925

19. Sahingur SE, Xia XJ, Alamgir S, Honma K, Sharma A, Schenkein HA. DNA From Porphyromonas Gingivalis and Tannerella Forsythia Induce Cytokine Production in Human Monocytic Cell Lines. Mol Oral Microbiol (2010) 25 (2):123-35. doi: 10.1111/j.2041-1014.2009.00551.x

20. Barth S, Kleinhappl B, Gutschi A, Jelovcan S, Marth E. In Vitro Cytokine Mrna Expression in Normal Human Peripheral Blood Mononuclear Cells. Inflamm Res (2000) 49(6):266-74. doi: 10.1007/pl00000206

21. Bomprezzi R, Ringnér M, Kim S, Bittner ML, Khan J, Chen Y, et al. Gene Expression Profile in Multiple Sclerosis Patients and Healthy Controls: Identifying Pathways Relevant to Disease. Hum Mol Genet (2003) 12 (17):2191-9. doi: 10.1093/hmg/ddg221

22. Corbi SCT, de Vasconcellos JF, Bastos AS, Bussaneli DG, da Silva BR, Santos RA, et al. Circulating Lymphocytes and Monocytes Transcriptomic Analysis of Patients With Type 2 Diabetes Mellitus, Dyslipidemia and Periodontitis. Sci Rep (2020) 10(1):8145. doi: 10.1038/s41598-020-65042-9

23. Sørensen LK, Havemose-Poulsen A, Bendtzen K, Holmstrup P. Aggressive Periodontitis and Chronic Arthritis: Blood Mononuclear Cell Gene Expression and Plasma Protein Levels of Cytokines and Cytokine Inhibitors. J Periodontol (2009) 80(2):282-9. doi: 10.1902/jop.2009.080347

24. Ørstavik D, Kerekes K, Eriksen HM. The Periapical Index: A Scoring System for Radiographic Assessment of Apical Periodontitis. Dental Traumatol (1986) 2(1):20-34. doi: 10.1111/j.1600-9657.1986.tb00119.x

25. Chalmers J, MacMahon S, Mancia G, Whitworth J, Beilin L, Hansson L, et al. 1999 World Health Organization-International Society of Hypertension Guidelines for the Management of Hypertension. Guidelines SubCommittee of the World Health Organization. Clin Exp Hypertens (1999) 21(5-6):1009-60. doi: 10.3109/10641969909061028

26. Grundy SM, Becker D, Clark T, Cooper RS, Denke MA, Howard J, et al. Executive Summary of the Third Report of the National Cholesterol Education Program (Ncep) Expert Panel on Detection, Evaluation, and 
Treatment of High Blood Cholesterol in Adults (Adult Treatment Panel III). Jama (2001) 285(19):2486-97. doi: 10.1001/jama.285.19.2486

27. Fouad AF, Barry J, Caimano M, Clawson M, Zhu Q, Carver R, et al. Pcr-Based Identification of Bacteria Associated With Endodontic Infections. J Clin Microbiol (2002) 40(9):3223-31. doi: 10.1128/JCM.40.9.3223-3231.2002

28. Livak KJ, Schmittgen TD. Analysis of Relative Gene Expression Data Using Real-Time Quantitative Pcr and the 2(-Delta Delta C(T)) Method. Methods (2001) 25(4):402-8. doi: 10.1006/meth.2001.1262

29. Basic A, Serino G, Leonhardt Å, Dahlén G, Bylund J. The Secretion of Cytokines by Peripheral Blood Mononuclear Cells of Patients With Periodontitis and Healthy Controls When Exposed to H2s. J Oral Microbiol (2021) 13(1):1957368. doi: 10.1080/20002297.2021.1957368

30. De Oliveira NF, Andia DC, Planello AC, Pasetto S, Marques MR, Nociti FHJr., et al. Tlr2 and Tlr4 Gene Promoter Methylation Status During Chronic Periodontitis. J Clin Periodontol (2011) 38(11):975-83. doi: 10.1111/j.1600051X.2011.01765.x

31. Wajant H, Pfeffer K, Pfizenmaier K, Scheurich P. Tumor Necrosis Factors in 1998. Cytokine Growth Factor Rev (1998) 9(3-4):297-302. doi: 10.1016/s13596101(98)00013-6

32. Boyce BF, Li P, Yao Z, Zhang Q, Badell IR, Schwarz EM, et al. Tnf-Alpha and Pathologic Bone Resorption. Keio J Med (2005) 54(3):127-31. doi: 10.2302/ kjm.54.127

33. Ryan S, Taylor CT, McNicholas WT. Systemic Inflammation: A Key Factor in the Pathogenesis of Cardiovascular Complications in Obstructive Sleep Apnoea Syndrome? Thorax (2009) 64(7):631-6. doi: 10.1136/thx.2008.105577

34. Dhingra R, Vasan RS. Biomarkers in Cardiovascular Disease: Statistical Assessment and Section on Key Novel Heart Failure Biomarkers. Trends Cardiovasc Med (2017) 27(2):123-33. doi: 10.1016/j.tcm.2016.07.005

35. Barreiros D, Pucinelli CM, Oliveira KMH, Paula-Silva FWG, Nelson Filho P, Silva L, et al. Immunohistochemical and Mrna Expression of Rank, Rankl, Opg, Tlr2 and Myd88 During Apical Periodontitis Progression in Mice. J Appl Oral Sci (2018) 26:e20170512. doi: 10.1590/1678-7757-2017-0512

36. Chang H, Zhang QY, Lin Y, Cheng N, Zhang SQ. Correlation of Tlr2 and Tlr4 Expressions in Peripheral Blood Mononuclear Cells to Th1- and Th2-Type Immune Responses in Children With Henoch-Schönlein Purpura. Int $J$ Clin Exp Med (2015) 8(8):13532-9.

37. Iwahashi M, Yamamura M, Aita T, Okamoto A, Ueno A, Ogawa N, et al. Expression of Toll-Like Receptor 2 on Cd16+ Blood Monocytes and Synovial Tissue Macrophages in Rheumatoid Arthritis. Arthritis Rheum (2004) 50 (5):1457-67. doi: 10.1002/art.20219

38. Papapanou PN, Sedaghatfar MH, Demmer RT, Wolf DL, Yang J, Roth GA, et al. Periodontal Therapy Alters Gene Expression of Peripheral Blood Monocytes. J Clin Periodontol (2007) 34(9):736-47. doi: 10.1111/j.1600051X.2007.01113.x

39. Fernández A, Cárdenas AM, Astorga J, Veloso P, Alvarado A, Merino P, et al. Expression of Toll-Like Receptors 2 and 4 and Its Association With Matrix Metalloproteinases in Symptomatic and Asymptomatic Apical Periodontitis. Clin Oral Investig (2019) 23(12):4205-12. doi: 10.1007/s00784-019-02861-9

40. Huang KT, Chen YC, Tseng CC, Chang HC, Su MC, Wang TY, et al. Aberrant DNA Methylation of the Toll-Like Receptors 2 and 6 Genes in Patients With Obstructive Sleep Apnea. PloS One (2020) 15(2):e0228958. doi: 10.1371/ journal.pone. 0228958

41. Haehnel V, Schwarzfischer L, Fenton MJ, Rehli M. Transcriptional Regulation of the Human Toll-Like Receptor 2 Gene in Monocytes and Macrophages. J Immunol (2002) 168(11):5629-37. doi: 10.4049/jimmunol.168.11.5629

42. Walsh SW, Chumble AA, Washington SL, Archer KJ, Sahingur SE, Strauss JF. 3rd. Increased Expression of Toll-Like Receptors 2 and 9 Is Associated With Reduced DNA Methylation in Spontaneous Preterm Labor. J Reprod Immunol (2017) 121:35-41. doi: 10.1016/j.jri.2017.05.003

43. Furuta T, Shuto T, Shimasaki S, Ohira Y, Suico MA, Gruenert DC, et al. DNA Demethylation-Dependent Enhancement of Toll-Like Receptor-2 Gene Expression in Cystic Fibrosis Epithelial Cells Involves Sp1-Activated Transcription. BMC Mol Biol (2008) 9:39. doi: 10.1186/1471-2199-9-39

44. Benakanakere M, Abdolhosseini M, Hosur K, Finoti LS, Kinane DF. Tlr2 Promoter Hypermethylation Creates Innate Immune Dysbiosis. J Dental Res (2014) 94(1):183-91. doi: 10.1177/0022034514557545

45. Diesel B, Ripoche N, Risch RT, Tierling S, Walter J, Kiemer AK. Inflammation-Induced Up-Regulation of Tlr2 Expression in Human
Endothelial Cells Is Independent of Differential Methylation in the Tlr2 Promoter Cpg Island. Innate Immun (2012) 18(1):112-23. doi: 10.1177/ 1753425910394888

46. Cardoso FP, de Faria Amormino SA, Dutra WO, Ribeiro Sobrinho AP, Moreira PR. Methylation Pattern of the Cd14 and Tlr2 Genes In Human Dental Pulp. J Endodontics (2014) 40(3):384-6. doi: 10.1016/j.joen.2013.11.024

47. Mutoh N, Tani-Ishii N, Tsukinoki K, Chieda K, Watanabe K. Expression of Toll-Like Receptor 2 and 4 in Dental Pulp. J Endod (2007) 33(10):1183-6. doi: 10.1016/j.joen.2007.05.018

48. Zardo G, Fazi F, Travaglini L, Nervi C. Dynamic and Reversibility of Heterochromatic Gene Silencing in Human Disease. Cell Res (2005) 15 (9):679-90. doi: 10.1038/sj.cr.7290337

49. Ching TT, Maunakea AK, Jun P, Hong C, Zardo G, Pinkel D, et al. Epigenome Analyses Using Bac Microarrays Identify Evolutionary Conservation of Tissue-Specific Methylation of Shank3. Nat Genet (2005) 37(6):645-51. doi: $10.1038 / \mathrm{ng} 1563$

50. Yan Y, Dalmasso G, Nguyen HT, Obertone TS, Charrier-Hisamuddin L, Sitaraman SV, et al. Nuclear Factor-Kappab Is a Critical Mediator of Ste20Like Proline-/Alanine-Rich Kinase Regulation in Intestinal Inflammation. Am J Pathol (2008) 173(4):1013-28. doi: 10.2353/ajpath.2008.080339

51. Kao YH, Chen YC, Cheng CC, Lee TI, Chen YJ, Chen SA. Tumor Necrosis Factor-Alpha Decreases Sarcoplasmic Reticulum Ca2+-Atpase Expressions Via the Promoter Methylation in Cardiomyocytes. Crit Care Med (2010) 38 (1):217-22. doi: 10.1097/CCM.0b013e3181b4a854

52. Barros SP, Offenbacher S. Modifiable Risk Factors in Periodontal Disease: Epigenetic Regulation of Gene Expression in the Inflammatory Response. Periodontol 2000 (2014) 64(1):95-110. doi: 10.1111/prd.12000

53. Fürst RW, Kliem H, Meyer HH, Ulbrich SE. A Differentially Methylated Single Cpg-Site Is Correlated With Estrogen Receptor Alpha Transcription. J Steroid Biochem Mol Biol (2012) 130(1-2):96-104. doi: 10.1016/j.jsbmb.2012.01.009

54. Rishi V, Bhattacharya P, Chatterjee R, Rozenberg J, Zhao J, Glass K, et al. Cpg Methylation of Half-Cre Sequences Creates C/Ebp $\alpha$ Binding Sites That Activate Some Tissue-Specific Genes. Proc Natl Acad Sci (2010) 107 (47):20311. doi: 10.1073/pnas.1008688107

55. Spainhour JCG, Lim HS, Yi SV, Qiu P. Correlation Patterns Between DNA Methylation and Gene Expression in the Cancer Genome Atlas. Cancer Inf (2019) 18:1176935119828776. doi: 10.1177/1176935119828776

56. Zhu H, Wang G, Qian J. Transcription Factors as Readers and Effectors of DNA Methylation. Nat Rev Genet (2016) 17(9):551-65. doi: 10.1038/ nrg. 2016.83

57. Fraga MF, Agrelo R, Esteller M. Cross-Talk Between Aging and Cancer: The Epigenetic Language. Ann N Y Acad Sci (2007) 1100:60-74. doi: 10.1196/ annals. 1395.005

58. Christensen BC, Houseman EA, Marsit CJ, Zheng S, Wrensch MR, Wiemels JL, et al. Aging and Environmental Exposures Alter Tissue-Specific DNA Methylation Dependent Upon Cpg Island Context. PloS Genet (2009) 5(8): e1000602. doi: 10.1371/journal.pgen.1000602

59. Jessop P, Toledo-Rodriguez M. Hippocampal Tet1 and Tet2 Expression and DNA Hydroxymethylation Are Affected by Physical Exercise in Aged Mice. Front Cell Dev Biol (2018) 6:45. doi: 10.3389/fcell.2018.00045

Conflict of Interest: The authors declare that the research was conducted in the absence of any commercial or financial relationships that could be construed as a potential conflict of interest.

Publisher's Note: All claims expressed in this article are solely those of the authors and do not necessarily represent those of their affiliated organizations, or those of the publisher, the editors and the reviewers. Any product that may be evaluated in this article, or claim that may be made by its manufacturer, is not guaranteed or endorsed by the publisher.

Copyright ๔ 2022 Bordagaray, Fernández, Astorga, Garrido, Hernández, Chaparro, Lira, Gebicke-Haerter and Hernández. This is an open-access article distributed under the terms of the Creative Commons Attribution License (CC BY). The use, distribution or reproduction in other forums is permitted, provided the original author(s) and the copyright owner(s) are credited and that the original publication in this journal is cited, in accordance with accepted academic practice. No use, distribution or reproduction is permitted which does not comply with these terms. 